\title{
Research of the Technology on internal rib and bulging forming
}

\author{
Ping $\mathrm{He}$ \\ Faculty of Aerospace Engineering \\ Shenyang Aerospace University \\ Shenyang, China \\ jzljzlu@126.com
}

\begin{abstract}
The forming of internal rib has more application in production, to meet the requirements of assembly, cooperate or increase the stiffness, it can be realized through the use of compressed coil or bulging coil tube forming rib forming, within or outside of the rib. It is for ribbed tube forming of schematic diagram, and it is rib for discharge voltage and pressure die fillet radius of rib, rib forming of depth is with the increase of discharge voltage, and pressure increases is with the increase of die radius, especially the influence of voltage is far greater than the radius. When the discharge voltage is from $5 \mathrm{kv}$ to $6 \mathrm{kv}$, rib depth increases obviously, local bulging forming is mainly not by right now, but rely on external metal flow.
\end{abstract}

Keywords-internal rib; stiffness; slapping; die fillet; bulging forming

\section{INTRODUCTION}

The forming of internal rib has more application in production, to meet the requirements of assembly, cooperate or increase the stiffness, it can be realized through the use of compressed coil or bulging coil tube forming rib forming, within or outside of the rib. Fig .1 is for ribbed tube forming of schematic diagram[1]. Fig .2 is rib for discharge voltage and pressure die fillet radius of rib, the influence of the figure is shown, rib forming of depth is with the increase of discharge voltage, and pressure increases is with the increase of die radius, especially the influence of voltage is far greater than the radius. When the discharge voltage is from $5 \mathrm{kv}$ to $6 \mathrm{kv}$, rib depth increases obviously, local bulging forming is mainly not by right now, but rely on external metal flow. Fig . 3 is rib for discharge voltage and pressure die fillet radius on rib roof thickness strain, the influence of the figure shows, with the increase of the discharge voltage and radius, the rib thickness strain also increase[2]. It can see from Fig .4, radius of $0 \mathrm{~mm}$ and $6 \mathrm{~mm}$ respectively is the rib roof thickness strain in $4 \mathrm{kv}$ and $6 \mathrm{kv}$ mutations. Pressure rib is in the process of tube bloom length strain, which is shown in figure, the figure shows that strain increases with radius tube bloom length. Tube billet length strain increases with voltage increasing, the voltage is $4 \mathrm{kv}$ up to a maximum, later, which has to do with external metal flows .

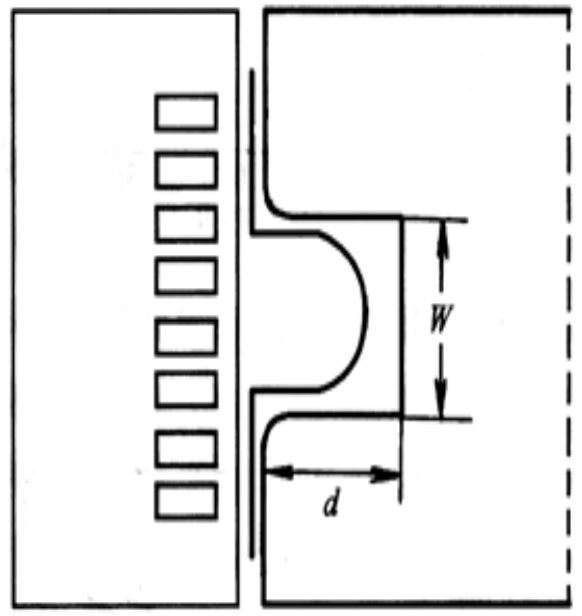

Figure 1. Schematic diagram of ribbed tube forming

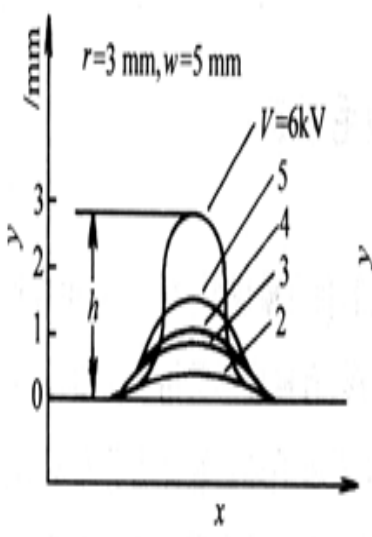

(a)

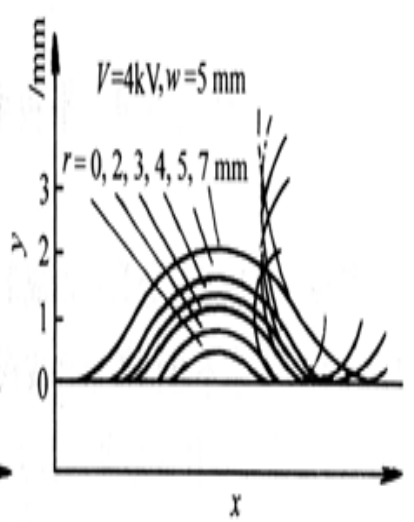

(b)
Figure 2. Influence on rib forming of die fillet radius 


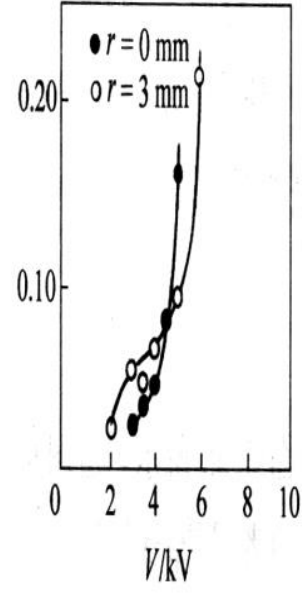

(a)

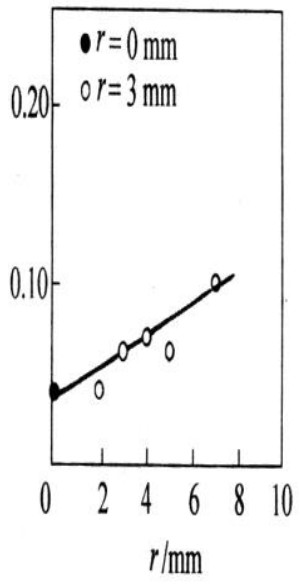

(b)
Figure 3. Pressure of die radius impact on thickness strain

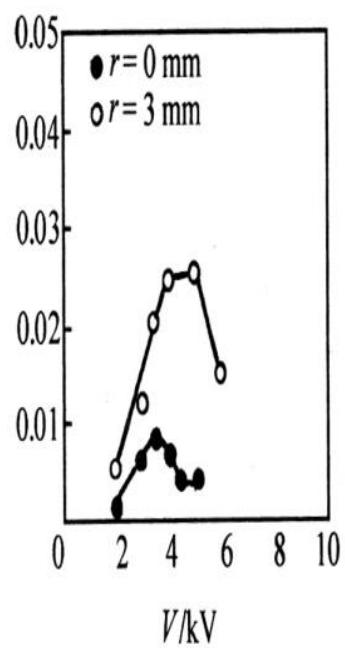

(a)

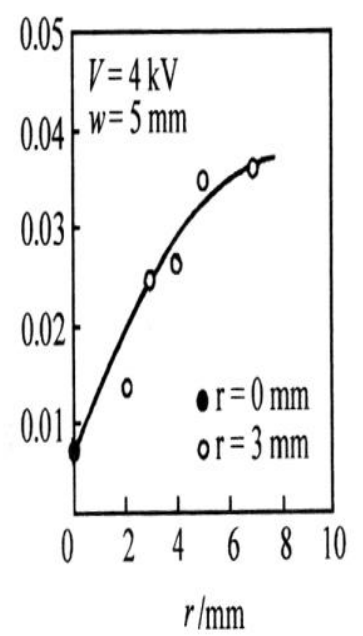

(b)
Figure 4. Voltage and pressure of rib discharge

\section{PIPE RELATIONS OF RELATIVE POSITION IS WITH FLARING RATIO}

The influence is pipe end position, when the end of pipe is beyond $10 \mathrm{~mm}$, magnetic pressure is almost zero. When the coil is no taper, it won't make the pipe deformation. When the Lc is negative, tube is expanding into a cone. Pipe relations of relative position is with flaring ratio . Regardless of the charging energy, when $\mathrm{Lc} / \mathrm{R}$ is 0.5 , pipe belling is the most. When $\mathrm{Lc} / \mathrm{R}$ is less than 0.5 , the pipe belling ratio decreases with the decrease of the $L c / R$, when $L c / R$ is greater than 0.5 , and which decreases due to the distance between the tube and coil the magnetic pressure of acting on the pipe, thus it reducing the flaring. As a taper coil is zero, due to the distance between the tube and coil, the basic is constant is flaring.

The taper pipe forming length is equal to zero by the coil in flaring, no matter how high, forming length is under the same discharge energy, tube and pipe near the clamping frame deformation is nearly the same, and the middle part is in the shape of straight uniform flaring, such as using coil with a taper shape, regardless of the length of the forming, the pipe is clamping frame[3], which is the same as in other parts of the deformation.

\section{THE MAGNETIC FIELD CAN PENETRATE THE NONCONDUCTIVE MATERIAL}

In the electromagnetic forming process, most of the deformation is in pulse pressure disappears. Under the effect of pulse pressure, the metal is obtained great acceleration, and got a lot of kinetic energy, metal forming is mainly depended on the kinetic energy to achieve. The electromagnetic forming is with pure electromagnetic properties, its forming process is not affected by mechanical inertia of the moving parts, so the electromagnetic forming can achieve rapid processing, which can work hundreds of times per minute. And the intensity of magnetic pulse can be accurately controlled, which is easy to realize mechanization and automation. The magnetic field can penetrate the nonconductive material, so to have a non-metallic coating or in forming the part with container. The electromagnetic forming is medium pressure on the workpiece with magnetic field, which is no mechanical contact. So the workpiece does not produce friction, which is no lubrication[4]. The electromagnetic forming is a single-mode forming, which simplified the mould manufacturing, to increased the processing flexibility. The electromagnetic forming parts are with high precision, residual stress low, and the springback is small. The process of materials are best used in below $0.15 \mathrm{um}$, the high resistance materials need to be adopt the high frequency equipment, the driven piece of structure is used on the tooling. Electromagnetic forming is often used in flat workpieces and the forming of tube blank.

\section{THE TUBE AND PLATE CONNECTION TECHNOLOGY MAY REALIZE THE CONNECTION OF TUBE AND THE CORE SHAFT}

The tube billet is bulging, and working coil is in the tube, when the pulse current is through the coil, a magnetic pressure pushs the tube outside billet mold. This method can be used for bulging and connection technology. Reducing is tube billet. Within the workpiece, the coil is inside the magnetic pressure to the workpiece of the compression modulus, which is often used for forming and connection process[5]. The flat blank is forming. A spiral flat coil is placed on a flat blank, when the pulse current is through the coil, the electromagnetic puts parts into the mould.This method can be used for flat blank forming, finishing and cutting. Electromagnetic forming is very suitable for tube and pipe, tube and plate connection technology may realize the connection of tube and the core shaft[6].

It is diversity that components of complex mechanical system failure mode and failure mechanism, failure prediction time is also very complex. In the process of the development of the system, with trials, in view of the different failure modes, improvement measures will be taken, and the reliability of the different failure modes may correspond to different growth patterns. But traditional reliability growth model, such as Duane model[7], the 
AMSAA model, usually only single reliability growth model is set up, which only discuss the time system failure and the failure number. the relationship between the considering the internal system corresponding to different failure mechanism is the effects of different improvement measures on the system reliability growth. This is a matter of engineering who has long been recognized, but because of the hybrid model parameter estimation problem is difficult, and thus has not an in-depth study.In this paper, through the establishment of a hybrid reliability growth model[8], it can reflect the different failure mechanism on the system reliability growth impact of different. To contain two kinds of failure mechanism of mixed AMSAA model is as an example in this paper, that is the main theory of this method.

Based on the chaotic state of complex mechanical system, forecasting process is as follows:

In the use of time, every time of acquisition state parameter of mechanical system is given, time sequence $\mathrm{X}$ $(\mathrm{t}), \mathrm{t}=\mathrm{i}$, shorthand for $\mathrm{x}_{0}, \mathrm{x}_{1}, \ldots, \mathrm{x}_{\mathrm{j}}$; it is calculating the maximum predictable dimension $\mathrm{T}$. The dynamic model of structural system is built. Within $\mathrm{T}$, it is the predicted under state sequence.

The plastic product manufacturing industry has been growing rapidly in recent years. One of the most popular processes for making plastic parts is injection moulding. The design of injection mould is critically important to product quality and efficient product processing[9]. Mould making companies, who wish to maintain the competitive edge, desire to shorten both design and manufacturing leading times of the by applying a systematic mould design process.

The mould industry is an important support industry during the product development process, serving as an important link between the product designer and manufacturer. Product development has changed from the traditional serial process of design, followed by manufacture, to a more organized concurrent process where design and manufacture are considered at a very early stage of design. The concept of concurrent engineering is no longer new and yet it is still applicable and relevant in today's manufacturing environment. Team working spirit, management involvement, total design process and integration of IT tools are still the essence of $\mathrm{CE}$. The application of the CE process to the design of an injection process involves the simultaneous consideration of plastic part design, mould design and injection moulding machine selection, production scheduling and cost as early as possible in the design stage.

This paper presents the basic structure of an injection mould design. The basis of this system arises from an analysis of the injection mould design process for mould design companies. This injection mould design system covers both the mould design process and mould knowledge management. Finally the principle of concurrent engineering process is outlined and then its principle is applied to the design of a plastic injection mould.

As shown, the material is ABS plastic, it is used for electrical connection of tube socket, the thickness is $4 \mathrm{~mm}$, not noted the rounded by $1 \mathrm{~mm}$, molded parts requests the certain strength, so as to avoid mechanical damage or deformation. The appearance of the parts is required roughness Ra6.3. The material of installing parts is plastics, belongs to the common thermoplastics, the forming is of good comprehensive performance, impact toughness, high mechanical strength, size stability, chemical resistance and good electrical properties, it is easy to shape and mechanical processing. Surface hardness and electrical insulating properties are balanced, in addition, their ability to resist shock is very excellent, it is larger of application temperature range, surface quality liquidity or is good. Molding shrinkage is smaller, which is usually in the form of $0.4 \sim 0.7 \%$. Heat capacity is low, plasticizing efficiency is high in the cylinder, rapid solidification is in the mould, the molding cycle is short, but the water imbibition content should be less than $0.3 \%$, the requirements of surface gloss plastic parts should be long preheating dry[10].

The parting surface is the second option. The two end of the parts are flat, according to the parting surface design principle, the parting surface design is on this plane. Because of the length of the upper and lower surface of different hole, it is obviously different package force, so to choose the parting surface on the surface. Comparing two options, one way is the part of the side core pulling, four cores are at the same time to participate in forming, the shape of the plastic parts size features ensures in good condition. By using the die blocks, and mould parts constitutes the edge part of the appearance. And the scheme of two cores is the size of non critical part, plastic flow is of a longer trip. A side core pulling is overmuch, processing complex, to make the mould the complexity, the overall increases, the second scheme is practical.

With smooth and rough rolling, cold rolling is under the mixed lubrication system of the experiment, the measured is strip roughness, and the corresponding relation of coefficient of friction. There are three ways used to simulate the friction. To simplify the semiempirical method, it only using a single wavelength irregularities to simulate the surface roughness, but according to the plate with a measuring device, the boundary friction coefficient varies with the change of the oil film thickness of measurement and research. Double wave model is to use a simple in contact with coulomb friction coefficient, on the surface, the change of double wave is rough amplitude.

By comparison, it shows the constant coefficient of friction in theory and the calculation of single wavelength, those cannot give a satisfactory prediction of friction coefficient values. By comparing the model prediction and experimental data, it found that the assumption that the border with higher speed and lower friction factor can obtain good consistency. Using rough roll and light board band is as shown, the friction along with the change of rolling speed is not significantly different. It showed that the composite roughness of the roll and strip roughness simulation is reasonable, and under the experimental conditions of longitudinal roughness, roll roughness of board band notch can not have significant effect on friction. Under the condition of low carbon steel in the mixed lubrication rolling experiment, it shows that the friction coefficient increases with the increase of compression, and decreases with the increase of rolling speed. The friction and lubrication parameters correlation is very good. 
Seen in it, all three formula gives the real value of the coefficient of friction, but the coefficient is some high; And all the formula predicts the friction resistance, which will reduce with the increase of velocity. At the same time, it also will increase with the reduction and friction coefficient is reduced, further proof that the deformation is the more and more contact, as well as the temperature increase and the vertical pressure of comprehensive effect. The two phenomena can make the friction resistance increases with reduction. The third kind of phenomenon is to increase friction reducing viscosity, all of these play an important role on the friction coefficient. It can be fully proved by the experimental data. The value range is very large, but which get the bigger influence on the calculation, results show mathematical model itself..

Metal forming process determines the applicability of the friction factor, test has proved to be cyclic compression experiment, in the experiments, the pressure is under the special size of the ring, and the size of the change is directly related to the friction factor, as shown in it.

\section{CONCLUSIONS}

The forming of internal rib has more application in production, to meet the requirements of assembly, cooperate or increase the stiffness, it can be realized through the use of compressed coil or bulging coil tube forming rib forming, within or outside of the rib. It is for ribbed tube forming of schematic diagram, and it is rib for discharge voltage and pressure die fillet radius of rib, rib forming of depth is with the increase of discharge voltage, and pressure increases is with the increase of die radius, especially the influence of voltage is far greater than the radius. When the discharge voltage is from $5 \mathrm{kv}$ to $6 \mathrm{kv}$, rib depth increases obviously, local bulging forming is mainly not by right now, but rely on external metal flow.

\section{REFERENCES}

[1]Feng. Jing , The Mixture of The Multimode System Reliability Growth Model,Computer Application Research Supplement, pp.60-61, 2003.

[2] Xu. Yuxiu, Complex Mechanical Fault Diagnosis Method of Fractal and Wavelet, Mechanical Industry Publishing House,Beijing, pp.24-25,2005.

[3] Weng. chaoxi, Reliability Growth, Science Press, Beijing, pp.130$131,1993$.

[4] Guofang, Reliability Data Collection And Analysis, National Defence Industry Press, p22,1995.

[5] Middleman. S, An introduction to fluid dynamics, John Wiley and Sons Inc,pp.24-25,1998.

[6] Gutowski T .G, Advanced composites manufacturing, John Wiley \& Sons Inc, New York, pp. 416-429, 1997.

[7] Rudd C D, Long A C, Kendall K N, Mangin C G E. Liquid molding technologies, Woodhead Publishing Ltd, London,pp.203-253, 1997.

[8] White Frank. M, Fluid mechanics (third edition), McGraw-Hill Inc, Highstown,pp.198-222, 1994.

[9] Wen.WeiDong, Prediction model based on the fuzzy reliability aircraft engine , Beijing, pp.322-323,2003.

[10]Liu.ZhanJun, Difficulty reliability prediction research of titanium plate stamping forming based on the fuzzy control, plastic engineering journal, Beijing,pp. 63-66,2005 (6) 